\title{
Attempts to Upcycle PET Wastes into Bio-based Long-lasting Insulating Materials
}

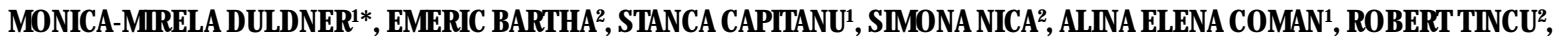 \\ ANDREI SARBU ${ }^{1}$, PETRU IVAN FILIP2 ${ }^{2}$, STELUTA APOSTOL ${ }^{1}$, SORINA GAREA ${ }^{3}$ \\ ${ }^{1}$ The National Institute for Research \& Development in Chemistry and Petrochemistry ICECHIM, 202 Spl. Independentei, 060021, \\ Bucharest, Romania \\ ${ }^{2}$ Institute for Organic Chemistry C.D. Nenitzescu of the Romanian Academy, 202B Spl. Independentei, 060023 Bucharest, \\ Romania \\ ${ }^{3}$ University Politehnica Bucharest, Faculty of Applied Chemistry and Materials Science, 1-7 Gh. Polizu Str., 011061, Bucharest, \\ Romania
}

\begin{abstract}
Following the green chemistry principles, three series of polyols with tailored chemical structures were obtained from PET wastes degradation via glycolysis and/or aminolysis and subsequent esterificationtransesterification and/or amidation reactions, using an organic catalyst. As cleaving agents there were used various mixtures of renewable or potentially renewable reagents, selected from those that can be obtained from biomass by already applied or investigated and eventually patented biochemical and/or chemical processes. The polyols were characterized by physical-chemical methods, ${ }^{1} \mathrm{H}-\mathrm{NMR},{ }^{13} \mathrm{C}-\mathrm{NMR}$ and FT-IR Spectroscopy, and tested in the synthesis of rigid polyurethane foams, showing appropriate properties for spray foams formation and leading to materials with properties similar to conventional spray foams.
\end{abstract}

Keywords: PET wastes, green chemistry, polyurethane insulating foams.

Depletion of fossil raw materials and increasing environmental problems associated with $\mathrm{CO}_{2}$ emissions enforced drastic measures for conserving the natural resources, preserving the natural environment and, if possible, reversing its degradation. On this line, a paradigm shift from an efficient economy, to a circular economy, based on concepts as: energy efficiency, use of renewable feedstock, waste prevention, recycling and upcycling, has been recognized as both a culture and a methodology for achieving sustainability [1]. In December 2015, the European Commission adopted an EU Action Plan for a circular economy, where it identified plastics as a key priority and prepared a strategy addressing their entire lifecycle, emphasizing reuse and recycling needs, since in the EU, the potential for recycling plastic waste is largely unexploited, while incineration rates of plastic waste remain high, producing additional $\mathrm{CO}_{\text {emissions [2]. }}$

Nowadays, PET recovery is more crifical than ever, given its positive effect on energy balance and decrease of $\mathrm{CO}_{2}$ emissions, especially as, due to their extremely high ${ }^{2}$ potential for recycling, PET wastes have been classified as secondary raw materials [3]. An approach to reducing environmental waste consisting of chemical depolymerization of PET and processing into oligomers for the ultimate formation of high-value polymeric materials has attracted significant interest in the scientific community [4], since chemical recycling of PET, a versatile process, complying with the principles of sustainable development [5], allows the preparation of various chemical structures of oligoesters. Glycolysis and aminolysis, or aminoglycolysis, are the most attractive methods of $P E T$ recycling, consisting in chemical degradation of the polymer by diols, polyols, alkanolamines, di- or polyamines, when ester linkages are broken and terminal hydroxyl or amino groups are formed. Glycolysis and aminolysis may be followed by other chemical reactions, including (trans)esterification or amidation with dicarboxylic acids (or derivatives), leading to oligoesters or oligoesteramides, precursors for various co-polymers [6-14].

In order to be sustainable, technologies must fulfil two conditions: natural resources should be used at rates that do not unacceptably diminish supplies over a long term and residues should be generated at rates no higher than can be readily assimilated by the natural environment [15]. Of these considerations arises the need for a green chemical industry, focusing on eliminating wastes, avoiding the use of toxic and/or hazardous reagents and solvents, generation of safer products, use of effective catalysts, replacing fossil resources with renewable raw materials $[16,17]$. Hence, there is currently a growing emphasis on the substitution of non-renewable fossil resources by renewable biomass as a sustainable feedstock for the manufacture of commodity chemicals and fuels [18-20]. The ideal scenario involves the valorisation of waste biomass generated as agricultural residues, by applying resource-efficient chemo- and bio-catalytic processes [21]. From a chemical perspective, nearly all building blocks for plastics can be made using renewable raw materials. Numerous chemical compounds have been subjected to intensive research in order to be obtained from biomass, starting with well-known polyols, derived from carbohydrates (e.g., sorbitol, anhydroalditols), aliphatic dicarboxylic acids (succinic, adipic, suberic), hydroxy-acids (citric, tartaric), hydroxybenzoic acids, di- or polyamines [22]. In addition, traditionally synthesized compounds from petroleum-based materials: diols and polyols such as ethylene glycol, polyethylene glycols, propanediol, glycerol, trimethylolpropane, pentaerythritol, ethanolamines, etc., and even aromatic dicarboxylic acids such as phthalic acids were intensively investigated from the above-mentioned point of view. [23]. Technologies have been developed and up-scaled, enabling, for some chemicals, commercial production [24]. There are also examples of chemical building blocks and materials partly based on renewable raw materials which for the moment cannot be entirely 
produced without using conventional chemicals. Benefits for the environment are, however, expected with the development and maturation of bio-based chemical processes and products, which require new approaches in research and development [25]. Consequently, the last decades have witnessed a real explosion of interestin using renewable building blocks in polymer synthesis $[26,27]$.

On the other hand, polyurethane rigid foams remain some of the most effective high-performance long lasting insulating materials, showing an outstanding combination of physical and mechanical properties [29] and, at the same time, the most feasible application of PET recycling products [6-11,14,22,23,27,29-31], while the versatility of PET chemical recycling process also opens new ways for generating bio-based products [32]. As an example, the lipophilic nature of vegetable oils used in the preparation of aromatic polyester polyols precursors for polyurethane foams, has increased their solubility in hydrocarbons, allowing the use of organic hydrocarbons (e.g. isopentane) as blowing agents. Polyester polyols for polyurethanes, obtained by chemical recycling of PET, with mixtures of diols, oxyalkyleneglycols and vegetable oils, optionally modified, are mentioned in a number of articles and patents [30-35]. Polyester-polyols from PET wastes incorporating isosorbide, a biomass derived diol, were also reported [36].

Most of the studies on PET chemical recycling use the classic transesterification reactions, in the presence of classical transesterification catalysts (metal salts or organometallic compounds), occurring at temperatures above $200^{\circ} \mathrm{C}$, and requiring a long reaction time $(4-8 \mathrm{~h})$. Therefore, a major challenge now is to deliver efficient sustainable and less energy demanding processes through developing green organocatalytic alternatives, while avoiding the barriers that occur with metal-based catalysis [37-39]. Literature reports mention mainly three classes of organocatalysts suitable for PET recycling: nitrogenbases, $\mathrm{N}$-heterocyclic carbenes and ionic liquids. Among these compounds, amidine-based organocatalysts (e.g. diazabicyclo (5.4.0) undec-7-ene-DBU) for glycolysis and guanidine-based organocatalysts (e.g. 1,5,7-triazabicyclo [4.4.0] dec-5-ene-TBD) for aminolysis of PET are the most popular and their applications are also patented $[40,41]$. The organocatalytic transesterification of PET in the presence of TBD or TBD derivatives as catalysts ( preformed or generated in situ during the PET depolymerization reaction) with ethylene glycol, diethylene glycol, isosorbide, ethanolamine, are also mentioned in some studies [4244].

However, a sequence of glycolysis/aminolysis, followed by (trans)esterification/amidation reactions, in the presence of organocatalysts, in order to obtain polyols with tailored properties, was not thoroughly investigated, to our best knowledge. Thus, following above mentioned guidelines, our study aimed at obtaining a range of polyols with tailored structures, suitable as precursors for polyurethane thermal insulating spray foams, from PET waste degradation via glycolysis and/or aminolysis, followed by esterification-transesterification and/or amidation reactions, involving various mixtures of renewable or potentially renewable reagents, selected from those that can be obtained from biomass by already applied or investigated and eventually patented biochemical and/ or chemical processes. The catalyst used, pursuing decrease of energy consumptions in terms of maximum synthesis temperatures and overall reaction time, was an amidinic bicyclic compound, namely DBU, which, although synthetically produced, is an alkaloid that can also be isolated from the sea sponge Niphates digitalis [45].

\section{Experimental part \\ Materials}

PET wastes from post-consumer bottles in flakes of 6-8 $\mathrm{mm}$, melting range $254-260^{\circ} \mathrm{C}$, intrinsic viscosity (according to ASTM D4603) of $0.77 \mathrm{dL} / \mathrm{g}$, washed and dried $6 \mathrm{~h}$ at 80 ${ }^{\circ} \mathrm{C}$; diethylene glycol (DEG), 1,2-propane diol (1,2PD); 2methy-1,3propane diol (MPD), 2,2-dimethyl-1,3propanediol (NPG) were purchased from Merck and used as received; 1,4:3,6-dianhydrosorbitol (isosorbide -IS) was purchased from Roquette and used as received, 2,22†Oxybis(methylene)bis(2-ethyl-1,3-propanediol) (ditrimethylolpropane -di-TMP) was purchased from Perstorp and used as received; monoethanol amine (MEA), diethanol amine (DEA), N-butyl diethanolamine (NBuDEA), diethylene triamine (DETA), succinic anhydride (SA), adipic acid (AA), phthalic anhydride (PA) were purchased from Sigma-Aldrich (Merck) and used as received; sunflower oil as food product, was purchased and used as received; 1,8-Diazabicyclo(5.4.0) undec-7-ene (DBU) was acquired from Merck and used as received.

\section{General procedure for synthesis of polyester-polyols}

A $250 \mathrm{~mL}$ round-bottom four-necked flask equipped with a mechanical stirrer, a thermometer, a reflux condenser and an inert gas (nitrogen) inlet was loaded with: $19.2 \mathrm{~g}$ (100 mmol) of PET, alkylene and/or oxyalkylene diols and/ or alkanolamines and/or amines listed above as raw materials, in various mixtures and ratios, 5-10 g (20-40 $\mathrm{mmol}$ ) of di-TMP, 4.5-9 g (about 5-10 mmol) sunflower oil and $0.59 \mathrm{~g}(0.6 \mathrm{~mL}-3.9 \mathrm{mmol})$ DBU catalyst. The flask was immersed in an oil bath preheated at $80^{\circ} \mathrm{C}$ and the glycolysis/aminolysis reactions were carried out at maximum $180^{\circ} \mathrm{C}$ for about $2.5-3 \mathrm{~h}$, until the PET waste disappeared and a clear mixture was formed. The reaction mixture was then cooled at $140^{\circ} \mathrm{C}$, when dicarboxylic acids (or derivatives) listed above as raw materials were added, in various mixtures and ratios. The reaction mixture was further heated at maximum $200-205^{\circ} \mathrm{C}$, for about 3-3.5 $\mathrm{h}$, while the stoichiometric amount of water is distilled off, until the acid number dropped preferably below $5 \mathrm{mg} \mathrm{KOH} /$ g.

Methods and techniques used to characterize the polyols

The Acid number $\left(I_{A}\right)$ was determined according to ASTM-D4662 -98. The Hydroxyl number $\left(I_{O H}\right)$ was determined according to ASTM-D4274-05. The average molecular weight (Mw) was calculated according to the end-groups method, using the acid number and hydroxyl number determined as mentioned above, withoutremoval of free glycols. The water content (\%) was determined by Karl - Fischer method, according to ASTM-D4672-05. The dynamic viscosity of the polyols was determined according to ASTM-D4878-03. ${ }^{1} \mathrm{H}-\mathrm{NMR}$ and ${ }^{13} \mathrm{C}-\mathrm{NMR}$ spectra of the polyols were recorded on a Bruker $300 \mathrm{MHz}$ spectrometer; FT-IR spectra of the polyols were recorded on a SHIMADZU 8900 spectrometer in $400-4000 \mathrm{~cm}^{-1}$ range, resolution of 4 $\mathrm{cm}^{-1}$, with ATR for solids and liquids.

\section{Polyols evaluation in synthesis of rigid polyurethane foams} Preparation method

The behaviour of the polyols in the foaming process was evaluated according to the cup test method, free rise process. The polyol component was prepared using the formula: polyether polyol Petol PZ 360-4G: 50 pbw.; polyether polyol PETOL PM 500-3F: 20 pbw; experimental polyol: 30 pbw; glycerol: 0.4 pbw; water: 2 pbw; 1,4Diazabicyclo[2.2.2]octane solution (DABCO 33LV) 
catalyst: 1 pbw, N,N-dimethylethanolamine catalyst: 0.8 pbw; potassium octoate in diethylene glycol (Dabco K15) catalyst: $0.25 \mathrm{pbw}$; dibuthyltin dilaurate (Jeffcat T12) catalyst: $0.12 \mathrm{pbw}$; hydrofluorocarbon (Solkane HFC365mfc/227ea) foaming agent: $20 \mathrm{pbw}$; silicon surfactant Tegostab 8461: 1.5 pbw.; tris(chloropropyl)phosphate) TCPP flame retardant - $15 \mathrm{pbw}$. The polyurethane foam was prepared following the formula: Polyol component -100 pbw; Crude MDI - 112 pbw corresponding to a volumetric ratio of $1: 1$, typical for the spraying equipment.

\section{Characterization of the rigid polyurethane foams}

The following characteristics were determined: i) reaction mixture's reactivity; ii) physical -mechanical properties of foams (according to ISO845, ISO844, ISO1209 and ISO2796); iii) thermal conductivity (according to ISO 8301); iiii) fire reaction (according to ISO 9773:1998) vertical flame test. Thermogravimetric analyses (TGA) were performed on a TGA Q500 (TA Instruments) device, platinum pan $100 \mu \mathrm{L}$, purge gas: nitrogen, $10.90 \mathrm{~mL} / \mathrm{min}$, operation method: dynamic heating from 30 to $700{ }^{\circ} \mathrm{C}$, at $10^{\circ} \mathrm{C} / \mathrm{min}$; Dynamic mechanical analyses (DMA) were performed on a TRITON DMA Q 800 ( TA-Instruments) analyser, temperature range: $30-240{ }^{\circ} \mathrm{C}$, ramp rate: $3^{\circ} \mathrm{C} /$ min, multi-frequency mode, single cantilever bending, 50 $\mu \mathrm{m}$ strain.

\section{Results and discussions \\ Polyols synthesis}

The experimental method used (fig. 1) is a melt glycolysis and/or aminolysis followed by esterificationtransesterification and/or amidation procedure.

In order to obtain polyols suitable as precursors for polyurethane rigid spray foams, namely showing an acidity number below $5 \mathrm{mg} \mathrm{KOH} / \mathrm{g}$, a hydroxyl number between 250-350 mg KOH/g, a functionality of around 2.2, a high content of aromatic and/or rigid moieties and, preferable, a state of liquid aggregation with as low as possible viscosity, as well as a high reactivity in polyurethane foam formulations, three series of polyols were synthesised, using various combinations of cleavage and chemical modification agents of PET wastes, and ratios thereof. In the first series rather flexible linear and branched diols were used for PET glycolysis, followed by esterification with relatively rigid dicarboxylic acids. The second series contains isosorbide, a rigid diol, whose behaviour in glycolysis reaction of PET wastes and synthesis of polyols for polyurethane foams has been studied before by our team $[36,42,46]$, alongside with diols with primary hydroxyl groups, and a flexible dicarboxylic acid used for esterification. Finally, in the third series, ethanolamines and a polyamine, in mixtures with customary diols were used for PET cleavage, followed by esterification with a flexible dicarboxylic acid. An amount of about 6 - 10\% by weight, based on total product, of sunflower oil, as such, was also added to the reaction mixtures, targeting a better compatibility with the polyurethane formulation. The chemical composition (reactants ratio) of the described polyols are presented in table 1 .

\section{Polyols characterization results}

Physical-chemical properties of the polyols

The polyols physical-chemical characteristics are very important in the process of foams formation, as well as in determining the properties of the final polyurethane polymer [47]. The physical-chemical properties of the herein described polyols are presented in table 1.

A detailed analysis of the chemical composition and physical-chemical properties of the obtained polyols marks as best chemical compositions, the variants P1G, in the first series, P2A in the second series and P3G in the third series. Some attempts of chemical composition optimization for the selected version of Series 1: experiments (P1K, P1L, P1M), also showed that polyols with lower viscosities can be obtained if, given the experimental composition, a compromise on the value of the acidity index, or a lower extent of the esterification reactions, is accepted.

\section{${ }^{1}$ H-NMR spectroscopy}

The chemical composition of the reaction products was investigated by ${ }^{1} \mathrm{H}-\mathrm{NMR}$ spectroscopy in deuterated chloroform (fig. 2). In the ${ }^{1 H} \mathrm{H}-\mathrm{NMR}$ spectra 5 zones can be identified: - the aromatic proton zone: $8,15 \mathrm{ppm}$ terephthalic acid (AT) from PET, usually split into a sharp peak indicating the presence of monomers and an envelope corresponding to several populations of oligomers of different molecular weights and 7.5 -7.68 ppm doublet corresponding to PA (fig. 2a); the area of double bonds protons in sunflower oil (SO) at $5.3 \mathrm{ppm}$, deformed signal, indicating several bonding modalities; $5.47 \mathrm{ppm}$ and 5.21 $\mathrm{ppm}$ - the IS proton area indicates esterification with both aromatic and aliphatic structural units but also significant amounts of free IS at 4.6 ppm [43,46]; glycolic proton area, indicating the following sequences: $4.7 \mathrm{ppm}$ - ethylene glycol interchain $\left(E_{\mathrm{ic}}\right), 3.7 \mathrm{ppm}$ - free $E G\left(E_{\mathrm{f}}\right), 2$ triplets at $3.58 \mathrm{ppm}$ and $2.72 \mathrm{ppm}$ - free DEG (DEG) and in the same area, between 4.0-3.3 ppm, one can notice end chain methylene protons (fig. 2a detail); 3.12 - $3.4 \mathrm{ppm}$ - the $\mathrm{CH}_{-}$$\mathrm{N}$ protons region of both the $\mathrm{n}$-Bu radical and the two branches of diethanolamine (fig. $2 \mathrm{~b}$ ); the protons of aliphatic acids: $2.5-2.6 \mathrm{ppm}$-SA (fig. 2a); $2.33 \mathrm{ppm}$ and $1.63 \mathrm{ppm}$ - with 2 branches - AA (fig. 2b); 0.85 ppm, 1.04 $\mathrm{ppm}, 1.05 \mathrm{ppm}$ - the area of methyl protons identified by 2 or 3 signals, indicating that the diols are linked into several types of esters. In the aliphatic region, between 2.2 and 1.4 ppm there are several signals indicating methylene protons
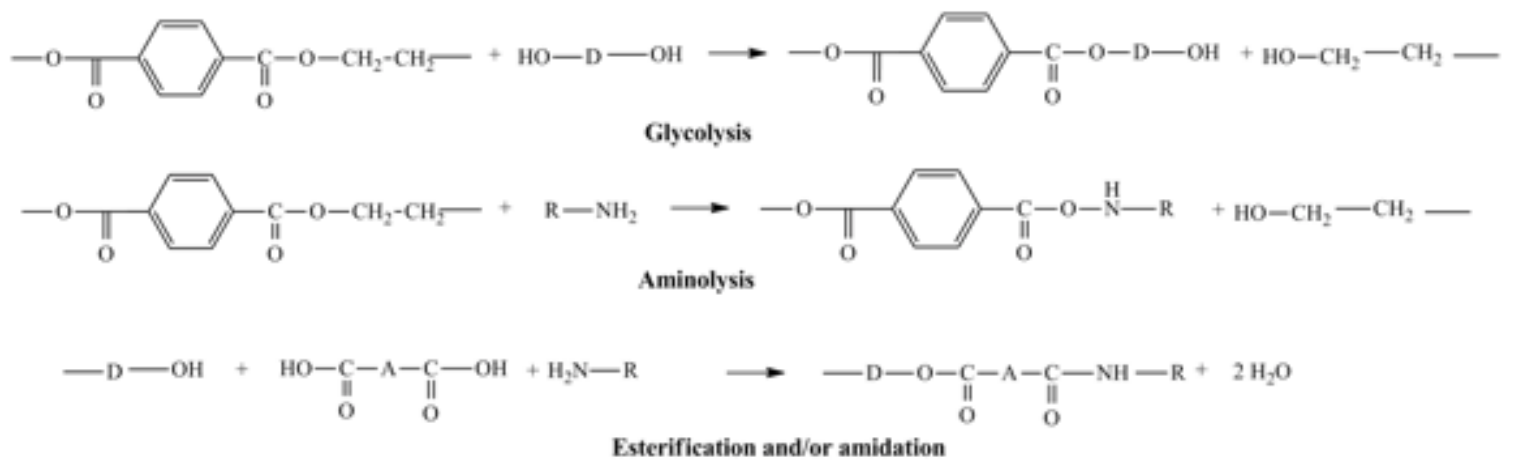

Fig. 1 Main reactions of PET cleavage and chemical modification 


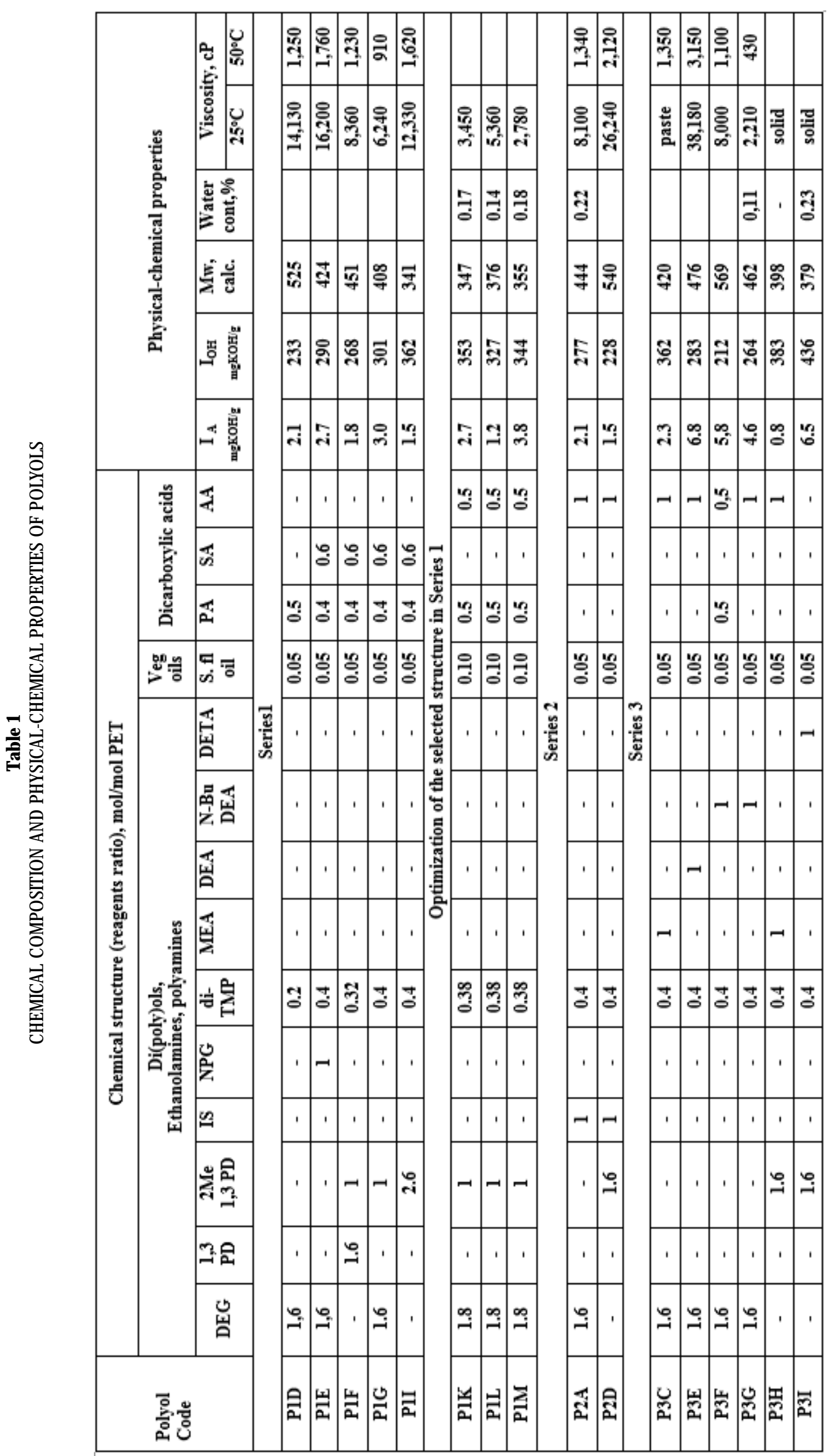

belonging to propyl and butyl moieties from diTMP and NBuDEA that could not be certainly assigned.

${ }^{13}$ C-NMR spectroscopy

By comparing the ${ }^{13} \mathrm{C}-\mathrm{NMR}$ spectrum of $\mathrm{P} 1 \mathrm{M}$ polyol (fig. 3) with the corresponding sunflower oil spectrum, one can notice that, while in oil, as such, the fatty acids appear as 2 signals (fig. 3a) ( $\mathrm{CH}_{\text {, and }} \mathrm{CH}$ in glycerol-carbonyl linked) in a ratio of $1 / 2$, at about 172.8-173.2 ppm, the same ratio of $1 / 2$ being found on the methyl groups at 14.06 and 14.10 ppm respectively, in the polyol sample the fatty acid -related signals (ig. 3b) from 173.2- 173.9 ppm appear multiplied 

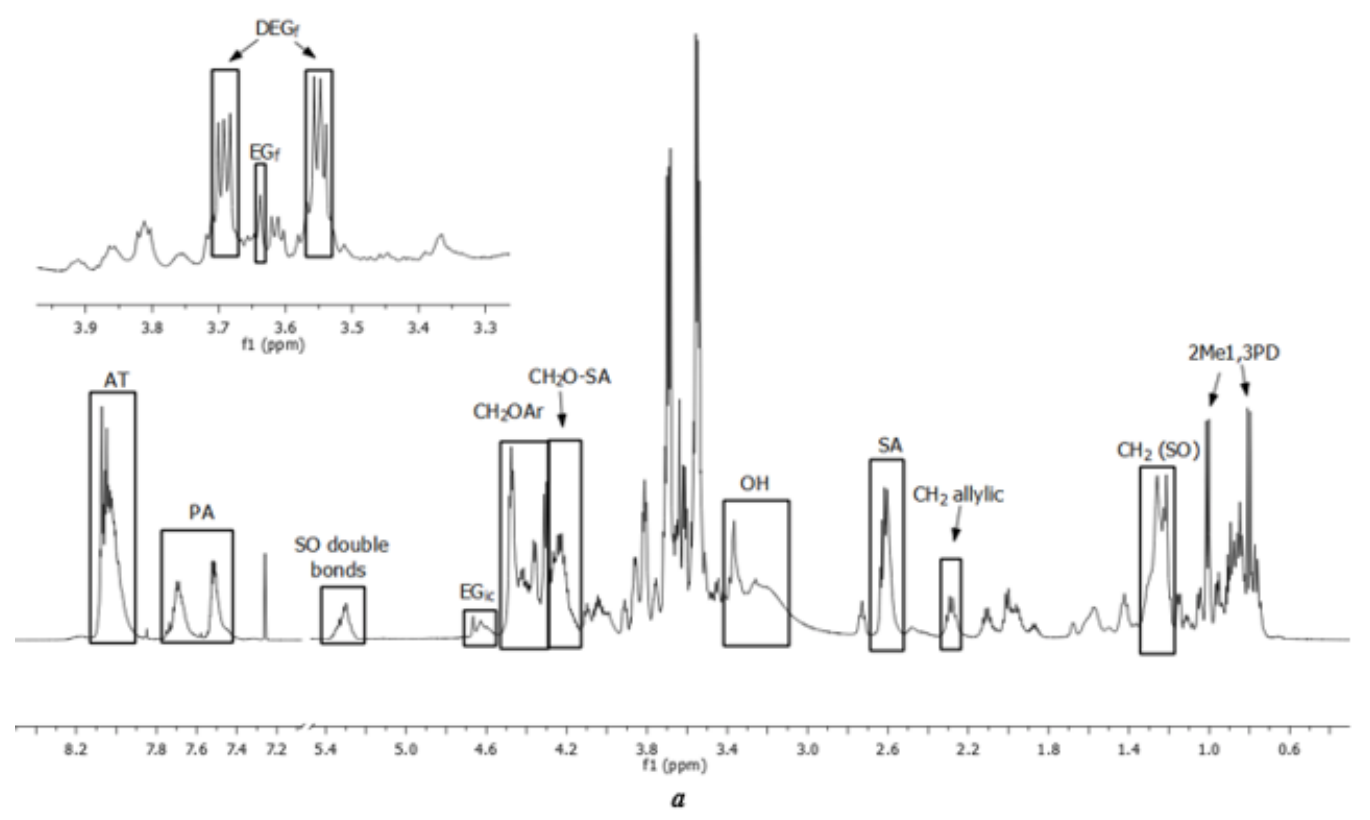

Fig. $2^{1} \mathrm{H}-\mathrm{NMR}$ spectra of the polyols: P1G with detail (a) and P3G (b)

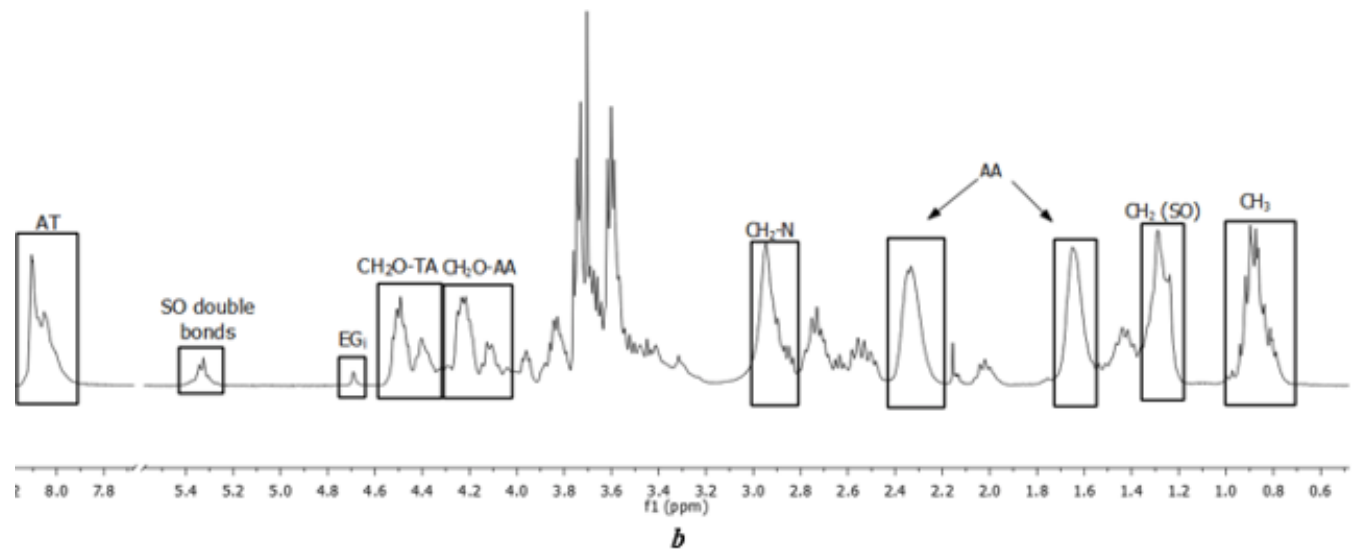

and move to higher values (line 172.85, for example, linked to $\mathrm{CH}$ from glycerine, no longer exists), indicating the existence of other neighbourhoods of $\mathrm{CO}$. This observation could indicate that the fatty acids derived from the oil were transesterified with the glycols or polyols present in the reaction mass. At the same time, the double-bond related signals from 127.9-130.2 ppm remain both as number and in similar form, indicating that the oil did not significantly degrade during the synthesis reaction of polyols.

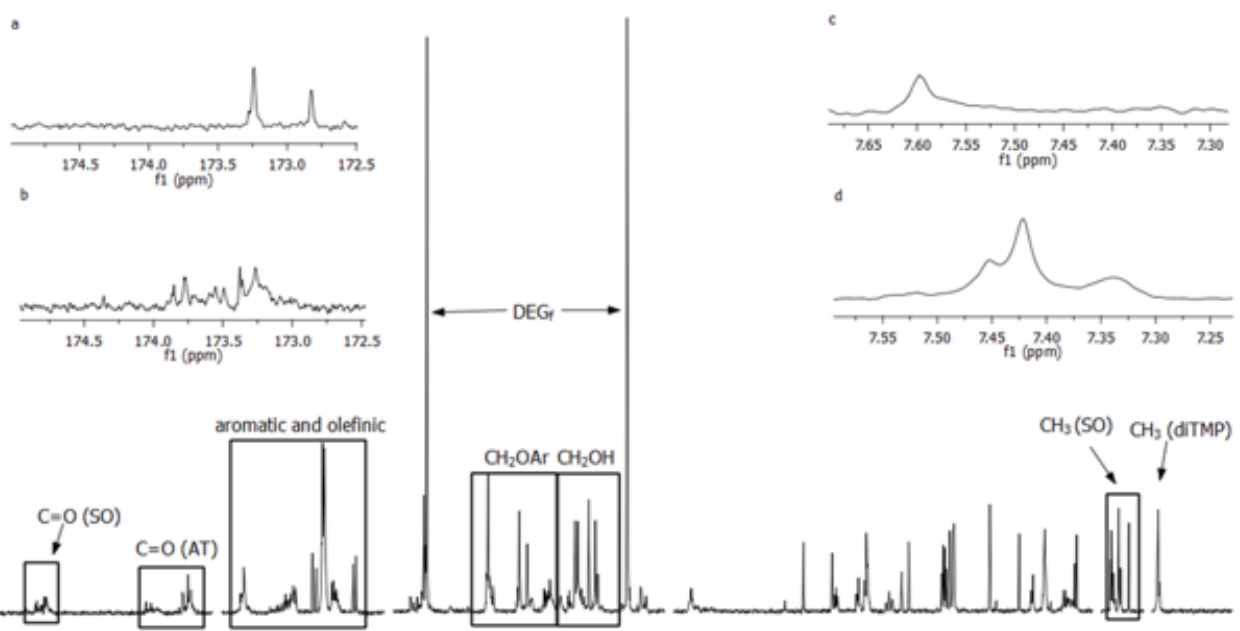

The ${ }^{13} \mathrm{C}-\mathrm{NMR}$ spectrum of P1M polyol also provides information about di-TMP transesterification in the final product (fig. 3d), compared to di-TMP as such (fig.3c).

${ }^{1} \mathrm{H}-\mathrm{NMR}$ and ${ }^{13} \mathrm{C}-\mathrm{NMR}$ spectra provided information on free glycol content and molar ratio of oligomeric fractions with various weights, as well as the distribution of structural units in different fractions and the way they are linked to each other. It has been pointed out that the products are complex mixtures of asymmetric oligoesters of the acids, including unsaturated fatty acids, and di(poly) ols present in the reaction mass and free di(poly)ols. The results
Fig. ${ }^{13}$ C-NMR spectra of polyol P1M with details (carbonyl region $-b$, methyl region of di-TMP $-d$, compared to sunflower oil, as such, carbonyl region -a and di-TMP, as such, methyl region $-c$ 
correlate with the molar ratios of the reagents and the results of the physical-chemical analyses.

\section{FT-IR Spectroscopy}

The polyols in the third series were characterized by FTIR spectroscopy, in order to highlight the formation of amide functional groups in the case of PET cleavage with mono and di-ethanolamines or diethylenetriamine, in admixture with customary glycols.

FT-IR Spectra (fig. 4) confirm the presence of ester and hydroxyl groups in all analysed polyols samples: strong band at $1720-1730 \mathrm{~cm}^{-1}$ and broad band characteristic of the $\mathrm{OH}$ group stretching vibration at $3400-3500 \mathrm{~cm}^{-1}$, but also of amide groups (narrow pick at $1620-1690 \mathrm{~cm}^{-1}$, associated with the $\mathrm{C}=0$ bond in amide group), in the case of P3C, P3I and P3E polyols, and absent for the P3G sample, wherein the amino group in NBu-DEA is totally substituted. In the spectra also appear stronger bands between $1245-1270 \mathrm{~cm}^{-1}$ which are assigned to carbonoxygen bonds (simply bonded) and medium bands at 2850 - $2960 \mathrm{~cm}^{-1}$ characteristic to carbon-hydrogen bonds (aliphatic and aromatic).

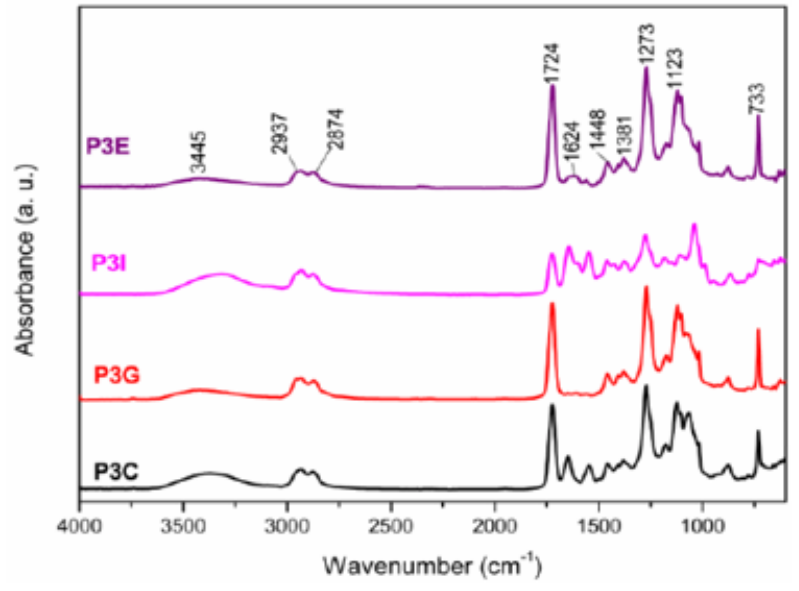

Fig. 4. FT-IR spectra of the polyols in Series 3

\section{Polyurethane foams preparation}

All the polyols obtained were tested in polyurethane foams formation. The solid or very viscous polyols were heated before blending with the polyether polyols, with which they formed homogenous and stable mixtures. The foams obtained had uniform colour and cellular structures.

\section{Polyurethane foams characterization}

The foaming systems and the polyurethane foams were characterized using the methods described above, in terms of reactivity, dimensional stability, mechanical properties and fire behavior. The results are presented in table 2 .

Thermogravimetric analyses (TGA)

The investigation of the polyurethane foams thermal stability, allowed determination of the temperature at which the weight loss is of $5 \%$, the temperature of the maximum weight loss rate and the residue at $700{ }^{\circ} \mathrm{C}$. The results are presented in table 2 .

\section{Dynamic mechanical analyses (DMA)}

The examination of the foams response as a function of temperature, time and deformation frequency allowed determination of the glass transition temperatures of the polyurethane foams, defining the upper limit of service temperature and reflecting the rigidity of the polymer, which impacts mechanical strength, dimensional stability, long term aging behaviour [48]. The results are presented in table 2 .

As the data in the table 2 demonstrate, the reactivity of the foaming systems and the physical-mechanical characteristics of the rigid polyurethane foams obtained fall within the ranges of specific values for sprayed rigid polyurethane foams, according to the formulations used. The tests carried out showed that the mechanical strength, thermal stability and thermal conductivity of the three series of polyurethane foams are comparable, the foams obtained with the polyols in Series 2 show a thermal resistance slightly increased and the foams obtained with the polyols in Series 3, containing alkanolamines in their structure, show a lower density than the foams obtained with polyols in Series 1. Both in terms of processability and

Table 2

REACTIVITY OF THE FOAMING SYSTEMS AND PHYSICAL-MECHANICAL PROPERTIES OF THE POLYURETHANE FOAMS

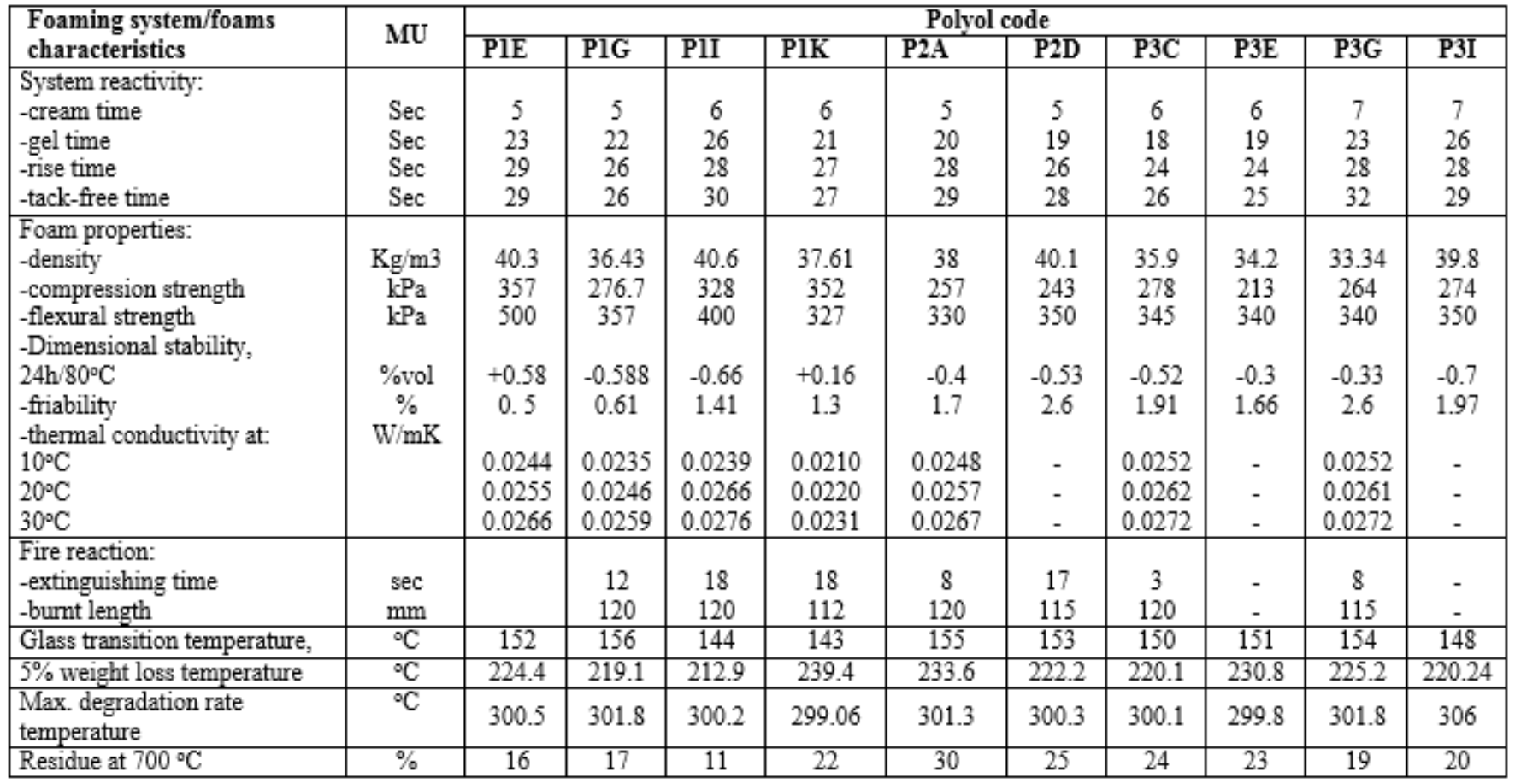


foams properties, the polyols P1G (Series 1), P2A (Series 2) and P3G (Series 3) stand out as having best properties for polyurethane rigid foams formation, especially due to their lower viscosities which allow for an easier mixing and a better homogenization of the foam formulation mixtures.

\section{Conclusions}

Three series of polyols with tailored structures, suitable as precursors for polyurethane thermal insulating foams, were obtained from PET waste degradation via glycolysis and/or aminolysis, followed by esterification- transesterification or amidation reactions. The synthetic protocol is consistent with the green chemistry principles, namely it involves various mixtures of renewable or potentially renewable reagents, it uses an organic catalyst which is effective for glycolysis, aminolysis, esterification and transesterification reactions, including trans-esterification of vegetable oils, and does not need to be isolated from the product, as long as it is known to catalyse the polyurethane forming reaction, as well. Except for the water resulted from the esterification or amidation reactions, no other byproducts or wastes emerge, the chemical composition of the products being fully suitable for reaction with diisocyanates, to form polyurethane rigid foams with mechanical properties, thermal stability, thermal conductivity and fire behaviour at least similar with conventional polyurethane thermal insulating foams.

Acknowledgement: The authors are grateful for the financial support of UEFISCDI, Complex Projects CDI, no 70PCCDI/2018 (MAUS)

\section{References}

1.CULLEN J. M., J ournal of industrial Ecology 21 (3), 2017, p. 483

2.*** European Commission, A European Strategy for Plastics in a Circular Economy 16.1.2018 p. 14

3.CHILTON T., BURNLEY S., NESARATNAM S Conservation and Recycling, 54, 2010, p. 1241

4. ${ }^{* * *}$ Proceedings of the National Academy of Sciences of the United States July 2016113 (28). p. 7722.

5.ACHILIASS.D (Ed) Material Recycling-Trends and Perspectives, 2012, 2. BARTOLOME L., IMRAN M. CHO, B., AL-MASRY, W., KIM, D.H, Recent Developments in the Chemical Recycling of PET, p. 65

6.COLOMINES G., ROBIN J., TERSAC G., Polymer, 46, 2005, p. 3230

7.PARDAL F. AND TERSAC G., Polym. Degrad. Stab., 91,2006, p. 2567

8.PATEL M. R., PATEL J. V., SINHA V. K., Polymer Degrad. Stab., 90 (1), 2005, p. 111

9.BOYADZHIEV M., LANGENSTRAßEN R., EFTIMOVA R., NENKOVA S., BEHRENDT G., TFH Wildau, Wissenschaftliche Beiträge 2007, p. 11 10.KACPERSKI M.; SPYCHAJ T., Polym. Adv. Technol. 10, 1999, p. 624 11.SPYCHAJ T., FABRYCY E., SPTCHAY S., KACPERSKI M., J. Mater. Cycles Waste Manag., 3, 2002, p. 24

12.SONY R. K., SINGH S., DUTT K. J. Appl. Polym. Sci., 115 (5), 2010, p. 3074

13.SHUKLA, S. R., HARAD, A. M. Polym. Degrad. Stab. 91 (8) 2006, p. 1850

14.*** Japan Patent 03A0649522, 2001

15.GRAEDEL T.E. Handbook of green chemistryand technology CLARK J., MACQUARRIE D.J (Eds..), New York, 2002, Green chemistry and sustainable development. p. 56

16. M. LANCASTER, Org. Process Res. Dev. 8 (2), 2004, p. 299

17. SHELDON RA. J. R. Soc. Interface 13, 20160087. http://dx. doi.org/ 10.1098/rsif.2016.0087
18. IMHOF P., VAN DER WAAL J.C. (Eds). Catalytic process development for renewable materials. Weinheim, 2013, Germany: Wiley-VCH; 1. MANZER L, VAN DER WAAL J.C., IMHOF P. The Industrial Playing Field for the Conversion of Biomass to Renewable Fuels and Chemicals, p. 18

19. SHELDON RA. Green Chem. 16, 2014, p. 950

20. DE JONG E, HIGSON A, WALSH P, WELLISCH M. Biofuels Bioprod. Bior. 6, 2012, p. 606.

21. TUCK C.O., PEREZ E., HORVATH I.T., SHELDON R.A., POLIAKOFF M. Science 337, 2012, p. 695

22. GANDINI A. Biocatalysis in Polymer Chemistry., 1.Monomers and Macromonomers from Renewable Resources, Loos K. (Edt.), 2011 WILEY-VCH Verlag GmbH \& Co. KGaA, Weinheim, p. 1

23. HARMSEN, P; HACKMANN, M.; Green building blocks for biobased plastics, Biobased processes and market development 16, 2013, Wageningen UR Food \& Biobased Research, 2013, p. 7, 13, 27, 49, 59 24. HARMSEN P., HACKMANN M. Biofuel Bioprod. Bior., 8, (3), 2014, p. 306

25. KAMM B., GRUBER P. R., KAMM M., Biorefineries - Industrial Processes and Products, Wiley-VCH Verlag GmbH \& Co. KGaA, Weinheim, 2012, p. 9

26. DONATE P. M, Chem. Biol. Technol. Agric. 1, 2014, p. 4,

27. IWATA T., Angew. Chem. Int. Ed. Engl, 54 (11), 2015, p. 3210

28. EVANS D.A.C Polyurethane Insulation: The Insulant of Choice for Low Energy Buildings -., Huntsman Europe BVBA, UTECH 2012, MAASTRICHT APR 2012

29.ABDEL AZIM A, ATTA A. M, EL-GHAZAWY R. A. Cell. Polym. 25 (1), 2006, p. 35

30.PABERZA A., FRIDRIHSONE-GIRONE A, CABULIS U. Polimery 60 (9) 2015, p. 572

31.WAGENER, E.H, et al. U.S. Pat. Appl. 20100280218

32.ATSUSHI, M., U.S. Pat. Appl. 20100029799

33.LORENZ, K., et al. EP 1923417 B1, 2009

34.SHIEH, D, J.; DELEON, A W O/2000058383

35.RICK T., et.al, PWIPO Pat. Appl. 2016028492 A1

36.DULDNER M., BARTHA E., IANCU S., CAPITANU S., NICA S., GAREA

S., MATERIALE PLASTICE 53 (3), 2016, p. 347

37.KIESEWETTER M. K., SHIN E.J., HEDRICK J. L., WAYMOUTH R. M., Macromolecules, 43 (5), 2010, p. 2093

38.FUKUSHIMA, O. COULEMBIER, J .. LECUYER M, ALMEGREN H. A., ALABDULRAHMAN A. M., FARES D. ALSEWAILEM, M., MCNEIL A., DUBOIS P., WAYMOUTH R. M., HORN H. W., RICE J. E., HEDRICK J. L., J. Polym. Sci. Part A: Pol. Chem., 49 (5), 2011, p. 1273

39.AL-SABAGH A.M., YEHIA F.Z., ESHAQ GH., RABIE A.M., ELMETWALLY A.E., Egypt. J. Petrol., 25 (1), 2016, p. 53

40.ALABDULRAHMAN A. M. et. al. U.S. Pat. 8,542,477 B2 /2013

41.HEDRICK, J.L. et al. U.S. Patent 8,492,504/ 2013

42.NICA ,S., HANGANU, A., TANASE, A., DULDNER, M., IANCU, S., DRAGHICl, C., FILIP, P. I., BARTHA, E., Rev. Chim.(Bucharest), 66, no.8, 2015, p. 1105

43.NICA ,S., DULDNER, M, HANGANU, A., IANCU, S., CURSARU, B., SARBU, A., FILIP, P. I., BARTHA, E., Rev. Chim. (Bucharest), 69 , no. 10, 2018, p. 2613

44.NICA, S., IONESCU, S., HANGANU, A., DULDNER, M., IANCU, S., SARBU, A., FILIP, P. I., BARTHA, E., Rev. Chim. (Bucharest), 69, no. 6, 2018, p. 1319

45.REGALADO, E. L., MENDIOLA, J., LAGUNA, A., NOGUEIRAS, C, THOMAS, O. P. Nat. Prod. Commun. 5, 2010, p. 1187

46.BARTHA, E., IANCU, S., DULDNER, M., VULUGA, M. D., DRAGHICl, C., TEODORESCU, F., GHERASE, D., Rev. Chim. (Bucharest), 62, no. 4, 2011, p. 401

47.IONESCU, M., Chemistry and Technology of Polyols for Polyurethanes, Rapra Technol. Ltd, Shawbury, Shrewsbury, Shropshire, UK, 2005, p. 31

48.HIEMENZ, P. C., Lodge T. P. 2007, Polymer Chemistry, 2nd Ed. Boca Raton, FL: CRC Press, p. 465

Manuscript received: 4.02 .2019 